\title{
ACCP REPORTS
}

\section{Report of the 2008-2009 Professional Affairs Committee: The Academy's Leadership Agenda for Meeting Academic and Practice Workforce Demands through Postgraduate Professional Education}

\author{
Caroline A. Gaither (Chair), ${ }^{a}$ David D. Allen, ${ }^{b}$ Douglas C. Anderson Jr., ${ }^{c}$ W. Greg Leader, ${ }^{d}$ \\ Laura A. Morgan, ${ }^{\mathrm{e}}$ Stanley S. Weber, ${ }^{\mathrm{f}}$ Jennifer S. Williams, ${ }^{\mathrm{g}}$ and Arlene A. Flynn ${ }^{\mathrm{h}}$ \\ ${ }^{a}$ College of Pharmacy, The University of Michigan \\ ${ }^{\mathrm{b}}$ College of Pharmacy, Northeastern Ohio Universities \\ ${ }^{\mathrm{c} C o l l e g e}$ of Pharmacy, The University of Georgia \\ ${ }^{\mathrm{d}}$ University of Louisiana at Monroe College of Pharmacy \\ ${ }^{\mathrm{e}}$ School of Pharmacy, Virginia Commonwealth University \\ ${ }^{\mathrm{f} S c h o o l ~ o f ~ P h a r m a c y, ~ U n i v e r s i t y ~ o f ~ W a s h i n g t o n ~}$ \\ ${ }^{\mathrm{g}}$ College of Pharmacy, University of Florida \\ ${ }^{\mathrm{h}}$ American Association of Colleges of Pharmacy
}

According to the Bylaws of the AACP, the Professional Affairs Committee is to study:

issues associated with professional practice as they relate to pharmaceutical education, and to establish and improve working relationships with all other organizations in the field of health affairs. The Committee is also encouraged to address related agenda items relevant to its Bylaws charge and to identify issues for consideration by subsequent committees, task forces, commissions, or other groups.

\section{COMMITTEE CHARGE}

President-elect Vic Yanchick charged the 2008-09 AACP Professional Affairs Committee to consider the leadership role of AACP and member institutions in supporting the anticipated demand for growth and development in postgraduate pharmacy education to meet workforce preparation needs for practitioners and faculty.

Specifically, the 2008-09 Professional Affairs Committee is charged to:

- Explore the role of AACP and its member institutions in supporting the anticipated demand for growth in postgraduate pharmacy education to meet workforce preparation needs for practitioners and faculty.

- Propose strategies for creating successful academic-practice partnership models for postgraduate professional education and practice that strengthen quality and promote access.

\section{HISTORICAL CONTEXT}

The Association has a history of thoughtful assessment of the role of the academy in postgraduate profes- sional education. AACP members as well as practice partners are struggling with workforce models for integration of academic pharmacy clinicians and practicebased clinicians to achieve synergistic patient care and education. The 2004-05 Professional Affairs committee recommended that AACP address "faculty roles in community-based partnerships for education and practice" taking into account issues such as: single and multi-site arrangements, pharmacist staffing and instruction expectation, corporate and academic expectations."1 The same needs exist in hospital/health system practice. A recommendation of the 2006 AACP Council of Deans Task Force on Post Graduate Pharmacy (Residency) Education addressed requirements for practice faculty preparation (full-time, part-time and adjunct) through postgraduate professional training (residency) or minimum equivalent experience. ${ }^{2}$ This task force also recognized that "such programs are essential in assisting colleges to achieve both short- and long-terms goals, not only for their educational programs but also for the other elements of their mission: service and scholarly activity."2

AACP has adopted policy supporting member colleges and schools involvement in postgraduate professional education and supporting accreditation of those programs. ${ }^{3}$ The policy statements resulted from the Board of Directors, the 1990 Academic Affairs Committee report, a 2002 task force report on the role of colleges and schools in residency training ${ }^{4}$, and most recently the Council of Deans.

Policy statements of the Association include:

- Specialization in pharmacy should be developed through postgraduate education or training 


\section{American Journal of Pharmaceutical Education 2009; 73 (8) Article S4.}

programs, such as residencies and fellowships. (Source: Academic Affairs Committee, 1990)

- AACP supports activities by colleges that enhance the quality and quantity of residency training programs in all pharmacy practice settings and recognizes that residency training is an essential element in developing differentiated (specialized) practice roles. (Source: Academic Affairs Committee, 1990)

- AACP supports accreditation by a federally recognized accrediting agency for all member institution affiliated residency programs. (Source: Task Force on the Role of Colleges and Schools in Residency Training, 2004)

- AACP recommends that all schools and colleges support postgraduate professional education and training, specifically residencies, as part of their mission. (Source: Council of Deans, 2005)

Historically, the academy supported residency training as a means of developing innovative practice and specialized practice roles. The Commission Papers ${ }^{5}$ support residency training as a means of specialization and as environments for creating innovations in practice which then are integrated into the professional program. Moreover, the Commission spoke to the academy's leadership role in facilitating expansion at that time. "While residency training has made significant strides over the years, the Commission believes that the profession is poised for enormous expansion in the responsibilities that it will assume, and residency training must support that expansion. Pharmaceutical education has a leadership role in facilitating this expansion by:

- increasing the number of residency programs;

- strengthening existing residency programs;

- identifying new areas of practice that may benefit from residency training;

- developing pilot residency programs in new practice areas to demonstrate their feasibility;

- promoting residency training to students and practitioners as career options;

- promoting the concept that experienced practitioners may acquire additional practice competencies through residency training." 5

Some twenty years later, growth in postgraduate pharmacy education is needed to meet the growing demand for pharmacy practice faculty and to meet society's and the profession's expectations for the future development of pharmacy practice models and occupation-related residency requirements for practitioners. Changes in the American Council of Pharmaceutical Education (ACPE) Standards 2007 (see Faculty and Staff Qualitative Factors and Guideline 25.1) dictate that "pharmacy practice faculty should possess additional professional training (residency, fellowship, or equivalent experience) and either have or be working toward credentials (for example, specialty certification) relevant to their practice and teaching responsibilities." 6 Two practitioner organizations $\left(\mathrm{ASHP}^{7}, \mathrm{ACCP}^{8}\right.$ ) have adopted positions on residency training as a future prerequisite for pharmacists delivering direct patient care. The American Pharmacists Association recently endorsed continued growth in accredited residency positions in all practice settings to meet future healthcare needs and adopted a position supporting post-graduate training for new PharmD graduates.

Given Association policy in support of postgraduate professional education, outstanding recommendations of multiple committees and task forces, the need to prepare the faculty and practitioners of the future to serve society and advance practice, AACP should take a leadership position in facilitating growth and development of postgraduate pharmacy education in member colleges and schools to meet these needs. ${ }^{2,5}$

\section{LEADERSHIP FOR RESIDENCY PROGRAMS}

\section{Exploring AACP and Member Institutions' Role in Supporting Anticipated Demand}

Demand for residency training currently exceeds capacity. ASHP data show that applications have exceeded the number of available positions for pharmacy residency training since 2003. ${ }^{9}$ Environmental factors originating in the academy, the profession and the public policy arena are expected to contribute to increased demand. Drivers for increased demand will likely include directives from the profession for additional and/or specialized training for graduates and established practitioners to meet future visions of pharmacy practice ${ }^{10}$ and workplace market dynamics such as occupational requirements for specific practice roles. Academic pharmacy's need to fill clinical practice academic faculty positions and the need to meet our service mission also contribute. Public policy directives such as the Institutes of Medicine Health Care Quality Initiative ${ }^{11}$ have recognized the increased importance and use of medications in the treatment and prevention of illness and the need for oversight and management of their use from both the healthcare delivery system and individual patient perspectives. Residency training programs have been cited as instrumental in addressing increased calls for improvements in the quality of healthcare and reduction of costs (e.g., " . . residents are necessary and critical for the future development of the pharmacy practice models, and most importantly for patient safety, as well)."

Moreover, growth in enrollments in Doctor of Pharmacy programs will result in increased numbers of 


\section{American Journal of Pharmaceutical Education 2009; 73 (8) Article S4.}

graduates who are the target audience for PGY1 residencies. Projections indicate that over the next decade pharmacy programs will graduate over 12,000 pharmacists annually, up from the current number of $9,800 .{ }^{12,13}$ With the projected growth in pharmacy enrollments, even if the percentage of graduates currently seeking advanced practice training through residencies (approximately 15$20 \%$ ) stayed constant, there would still be unmet demand if the number of residency programs/positions doesn't increase.

With the current environmental factors and previous Association direction in mind, the committee discussion critically considered the role for academic institutions in engaging in postgraduate professional education (specifically residency training), identified the need for evidence to show value for participation to all participants, and the need for tools and program enhancements to support academic and scholarly preparation. The committee also discussed facilitators and barriers to academic participation and drew upon the information gathered in the "Call for Successful Practices" for examples. ${ }^{14}$

\section{Leveraging Resources and Demonstrating Value}

Chief Executive Officer (CEO) pharmacy deans need to be convinced that instituting and financing college or school-based post graduate year (PGY) pharmacy residency programs benefit their institution. In challenging economic times justification of resources to support residency training is going to be even more difficult. How can we make the most effective argument that collegebased residency programs have economic value for the college? Thus, evidence that demonstrates the value to colleges and schools and the academic institution as a whole will need to be robust because such evidence enhances the likelihood of securing funding.

A value proposition represents a clear statement of the tangible results a stakeholder gets from using a product or a service. ${ }^{15}$ This statement convinces potential users that one particular product or service will add more value or better solve a problem than other similar offerings. A good value proposition focuses on meeting unmet needs in a particular situation. In considering the value proposition for residency training, colleges and schools and in particular CEO deans must demonstrate to upper administration the rationale for pursuing PGY residency programs as part of the overall mission of the college. Faculty support and conviction for mission-driven engagement in residency training is critical. Further, external stakeholders must view residency training as an initiative that should be undertaken as part of the mission.

What is/are the leverage point/s that will enable a college administration to pursue additional resources to sup- port development of residency training? This is a key question in gaining new financial support for residencies. Justification to seek such support is critical if colleges choose to undertake this as part of their mission. The following questions identify key information needed to support requests for additional financial resources for residency training in a college. These questions are the beginning of a thread of inquiry leading to evidence for effective strategies and demonstration of the value proposition for college engagement in residency training.

- Is there evidence to support the concept that college-based residency training programs result in individuals better trained to become pharmacy practice faculty? What level of education and training is necessary to prepare clinician-researchers to be successful in tenure track positions, and can college-based programs do this better than institution-based programs?

- Is it possible to combine residency training with masters degree programs that can result in a revenue stream from the educational portion of the program that can financially support the residency aspect? How would promotion of residency training affect other post-graduate options such as MS or $\mathrm{PhD}$ programs? How can they be complementary?

- Does having residency training as part of the college facilitate hiring pharmacy practice faculty? Retaining them? Will training residents increase the effectiveness and/or efficiency of current faculty related to their responsibilities of teaching and scholarship? How does training residents impact promotion and tenure? How can postgraduate professional education be employed to increase the pool of practitioners qualified for recruitment to faculty positions?

- Does college-based residency training have an impact on educating pharmacy students and particularly their experiential education? How can postgraduate professional education be conceptualized as central to the mission of all colleges of pharmacy? What are the conversations faculty would have about mission to conclude that postgraduate professional education fits?

- Is participation in residency training a mechanism to develop preceptors for experiential education? Are pharmacists who are residency-trained more likely to serve as preceptors?

- Is the reallocation of vacant or newly created pharmacy practice faculty lines to support residencies a viable approach to creating collegebased residency opportunities? 


\section{American Journal of Pharmaceutical Education 2009; 73 (8) Article S4.}

- Will there be positions available for residencytrained pharmacists to use the skills they have acquired? Will enough residency positions be available to meet demand by students and institutions that need residency-trained pharmacists?

Answers to these and other pertinent questions will help build the case for support. It is incumbent on academic pharmacy to take leadership for articulating a pharmacy research agenda to show evidence of the value of postgraduate professional education. Such evidence should focus on developing innovative practice arrangements for faculty, services, delivery of care, patient care outcomes and leadership. It is critical to articulate the return on investment to the college so that the rationale for allocating resources to college-based residency training is clear. The committee suggests that possible strategies to encourage this research within academic pharmacy might include commissioned papers, a focus in the American Journal of Pharmaceutical Education perhaps with a special supplement or member affinity groups of the Association (e.g., Pharmacy Practice or Social Administrative Sciences Sections) might consider adopting this as their agenda in the future.

\section{Potential Benefits to Academic Pharmacy for Engagement in Residency Training Programs}

What motivates colleges to invest? Colleges cite raising the level of pharmacy practice and improving practice environments as Advanced Pharmacy Practice Experience (APPE) sites; creating opportunities for faculty scholarship through mentoring research projects; cultivating and potentially recruiting future preceptors and faculty members; gaining faculty extenders as residents participate in the classroom; enhancing pharmacy services and patient care at the practice partner sites; and stronger ties between the academic institution and the medical training programs in the state. ${ }^{14}$ Residents in the community setting have been involved in reimbursable patient care activities such as Medication Therapy Management and in designing innovative services such as immunization clinics which serve to advance patient care and provide opportunities for faculty research and student experiential education. In many cases, partnerships with practice sites for residency programs have led to enhanced collaborations yielding positive impact to the teaching, professional service, and scholarly goals for the practice partner and academic institution. ${ }^{14}$

Colleges and schools. Cost-savings may be realized with residents providing coverage of teaching, precepting and mentoring for pharmacy students. A well-developed residency program can provide support for faculty preceptors and serve as a training ground for new pharmacy practice faculty. ${ }^{14}$ However, cost-savings can be off-set in the short term by the time it takes from other faculty to train and interact with pharmacy residents. There is an initial investment of resources in development. "Financial and faculty resources are required to effectively develop residency programs with sufficient practice and educational abilities. Teaching experiences must be developed which complement the practice experience, support the educational mission of the College, and adequately prepare the residents for entry-level faculty responsibilities. Faculty must also have sufficient time to dedicate to training residents, particularly early in the training year. Some faculty will need guidance in supervising residents so that they provide the proper balance of supervision and independence." 14 Residents allow colleges to create new or expand existing clinical programs such as Medication Therapy Management programs, which may contribute to a revenue stream. Residents can bolster scholarship and clinical research programs with the potential to increase extra-mural funding for colleges and schools. In a parallel context to graduate students in the basic sciences, residents can serve as clinical practice faculty extenders allowing faculty more time for scholarly activities. In addition, faculty can serve as research advisors or co-author papers with residents to increase scholarly activity.

Residents can also serve as bridges or liaisons to various types of healthcare delivery systems that allow college/school-based faculty the opportunity to have a direct role in shaping the healthcare delivered by pharmacists in practice. This direct input can lead to the development of research and interdisciplinary training programs that support scholarly activities important to the success of academicians. Practice models can be tested and the results used to provide information to inform curricular offerings needed for current and future pharmacy practice.

Residency programs can serve as a bridge between practice and traditional academic graduate programs which allows the development of clinical research scientists at both the MS and PhD levels. The University of Texas at Austin currently has three combined residencyMS programs to prepare researchers and clinicians in the areas of a) health outcomes, pharmacoeconomics, social and behavioral pharmacy, and pharmacy management; $b$ ) psychiatric pharmacy and mental health outcomes research; c) pharmacotherapy practice, research and education. The programs are typically two years in length, and integrate residency and graduate training. ${ }^{14}$

Expansion of the types and varieties of residency program training sites assists with the mission of pharmacy education in preparing individuals who will be leaders in the profession. This also represents a way for colleges and 


\section{American Journal of Pharmaceutical Education 2009; 73 (8) Article S4.}

schools to become involved in their graduates' pursuit of lifelong learning.

Residency programs can extend the reputation and profile of colleges and schools and can foster and improve relationships between the college/school and institutions/ agencies within the community, and within academia. Utilization of college/school resources such as distance learning technologies to connect residents and preceptors can likewise increase the state and regional footprint of an academic institution.

Residency training sites can also be used to develop and sustain educational sites needed for both introductory and advanced practice experiences for pharmacy students as well as prepare residents for educator roles as preceptors. There is evidence that residency partnerships in hospitals and health-systems are correlated with partnerships for experiential education. ${ }^{16}$ This finding suggests that as colleges and schools consider program development initiatives in their planning, they may want to engage in dialogue with hospital and health-system administrators in a multilevel partnership model for the education of students and residents thus providing an environment for creating integrated training models and a strategy for increasing capacity in experiential education.

Pharmacy students. Academic involvement in residency training may have educational benefits for pharmacy students. Pharmacy residents who participate in training of pharmacy students provide role models for students and instruction from individuals very much like themselves. They can enhance students' vision of what pharmacy practice can be like and how they can contribute. Seeing and interacting with a pharmacy resident fosters the expectation that students be involved in the education process as they transition into practice. Residency programs offer pharmacy graduates a pathway to distinguish and differentiate themselves from their peers and help them prepare for board certification examinations.

Practice sites and employers of pharmacists. Providing practice sites with more residents could lead to the development and sustainability of patient care services which can be carried out by residents and students. These services can potentially represent additional revenue streams for the practice setting and enhanced healthcare for patients. Residents' clinical activities and research projects can serve to raise awareness for the need for enhanced pharmacy services with physicians.

Patients, caregivers and family members. Having more residents in the system may improve the quality of medication use and reduce adverse drug events through the development of direct patient care services as noted above. Many of the programs are very labor intensive for a pharmacist to provide. Research has shown that the more assistance a pharmacist has at a practice site, the more likely he or she will offer direct patient care services. ${ }^{17}$ These programs assist and empower patients to become managers of their own medications and health.

Payers. Residents can assist payers of healthcare through providing services related to medication use which has escalated in cost over time. With the use of residents at various practice sites, a reduction of healthcare costs may be achieved. There is potential for healthcare cost reduction at the policy level (e.g., formulary recommendations, medication use evaluations, etc.) and at the individual patient care level through therapeutic plans, monitoring and appropriate use of medications. These interventions may result in reduction of hospitalizations due to adverse drug events, inadequate treatment, or therapeutic misadventure, and overall improvement of quality care.

Practicing pharmacists. Innovative residency training programs that use distance-learning technology or incorporate other nontraditional formats can be valuable to pharmacists who want to obtain additional skills. This could be an untapped market for colleges and schools of pharmacy and an additional way to provide continuing professional development for their graduates. Involvement with residency programs may foster individual professional growth and job satisfaction.

Other healthcare professionals. Interdisciplinary training opportunities with medical residents, advanced practice nurses, social workers, public health educators and others which can help develop the team approach to patient care are called for by many of the leaders in healthcare and education.

Documentation, tracking and appropriately designed research studies which follow residency-trained pharmacists in practice are needed to provide evidence which demonstrates the value proposition of residency training for the specific needs or environment of each of these stakeholders.

\section{Strategies for Creating Successful Academic-Practice Partnership Models}

What models can be built for college/school-based residency programs that take advantage of the academic contribution? Are there models of partnerships with practice environments where the return on investment has been demonstrated to be positive for the college? Is it possible to structure such relationships so as to minimize the college/school's financial support for the residency training program? Many current models for pharmacy residency training remain largely outside the influence of academic pharmacy. Historically, colleges and schools have not universally invested in the post-graduate residency experience. 


\section{American Journal of Pharmaceutical Education 2009; 73 (8) Article S4.}

Although there have been recent advancements and growth in community-based practice experiences, residencies exist primarily in health-system pharmacy practice settings. Traditionally, in academic medical centers residencies have been funded and managed primarily through the institution. Is cost-sharing between college resources and utilization of programs like Medicare pass-through reimbursements to hospitals the best approach?

While a single entity may be effective in providing residency training, partnerships involving two or more entities allow for the pooling of resources and expertise. Sharing financial and administrative resources can streamline and standardize marketing, recruitment activities, and accreditation processes. Such partnerships may allow for the development of postgraduate training programs in practice sites or institutions that previously felt unprepared to offer this level of education. For a strong partnership to exist, all parties must provide resources and all parties should benefit from the process or end product. To this end, whether the practice site or the educational entity holds the accreditation is not as important as both parties materially and significantly participating in the partnership in a way that resource utilization and benefits are mutually shared and that a shared vision for the educational program exists.

To gather information about strategies currently employed at member colleges and schools, the 2008-09 Standing Committees engaged in a "Call for Successful Practices" relevant to the charges. The Professional Affairs Committee called for descriptions in 5 key areas related to college/school involvement in conducting residency programs ${ }^{14}$ :

- Partnerships/models for structure, administration and funding

- Residency training programs incorporating preparation for academic career; and descriptions of how participation in residency programs contributes to faculty and practice development

- Combined residency/degree programs

- Use of technology to bridge programs/disciplines

The call to AACP members resulted in 9 descriptions of partnership models from schools involved in both PGY1 and PGY2 residency programs; 6 descriptions of residency programs designed to prepare clinicians for academic roles; 3 descriptions of residency program/MS degree combination; and 1 each for contribution to faculty development and use of technology to enhance the residents' experience and bring resources to the practice site. The successful practice submissions ${ }^{14}$ from all categories are published separately in a compendium on the AACP website as a method for sharing strategies and models that others may adopt. Contact information for each program is included so that interested parties will be able to network. This web publication strategy also partially addresses the committee's recommendations to make the level of involvement in residency training of our member institutions more visible and available for sharing and replication.

As identified in members' submissions ${ }^{14}$ regarding college/school involvement in conducting residency programs, models do exist that demonstrate that members of the academy can find mutual benefit from participation with healthcare facilities to provide post-graduate clinical training. Colleges report that partnering allows for sharing financial and administrative resources to streamline and standardize the marketing, recruitment activities, and accreditation process with improvement in recruiting efforts.

If the residency program is administered by a school or college for a practice site, the site will benefit from the development of a central administrative structure that can be used to streamline the accreditation process. The academic institution can provide assistance with quality assessment and measurement of outcomes of residency training for the practice site.

Consideration should be given to investigating potential benefit of applying the graduate medical education accreditation model to pharmacy post-graduate education. This model would allow the college/school to hold the accreditation and approve specific training sites. This allows for centralization of the administrative functions and responsibilities, including the accreditation process. This may further solidify these partnerships and allow the development of partnerships with entities or in areas that lacked the necessary expertise. ${ }^{4}$ For this model to work, accreditation of the residency programs would have to move toward a programmatic evaluation as opposed to assessment of the individual practice sites. ${ }^{4}$

Expansion of partnerships into nontraditional settings. Traditional settings and partners have included health systems (private, public, academic or community and government). Federal agencies such as the Veterans Administration, Public Health Service, military, or other agencies with potential funding streams available to support residency training have partnered with academic institutions. Particular care should be given to identifying partnership models that allow for expansion of residency training programs to non-traditional areas such as community pharmacies, ambulatory care clinics, primary care clinics, managed care environments and the efficient use of resources in these environments. Attention should be given also to the use of technology, especially video conferencing, as a tool to expand residency penetration, 


\section{American Journal of Pharmaceutical Education 2009; 73 (8) Article S4.}

particularly in rural areas and as a method of creating community among residents and preceptors in a geographic area.

\section{Preparation for Faculty Roles}

Residency training is considered a foundational component in the career preparation for clinical practice faculty and is contained in a "should" statement in accreditation guidelines. How well do traditional residencies prepare pharmacists for careers in academia? What are successful models for college-based residency programs to prepare practitioners for academic roles? Could combining residency with a Master's degree or other academic program (degree or certificate) to prepare faculty be a focus for academic institutions?

Teaching certificate programs or teaching workshops are included in residency programs. Of the six schools contributing submissions to "Residency Training as a Foundation for Faculty Preparation," all six mention a formal training opportunity and/or mentorship program for residents to enhance or refine their teaching skills. Schools also report that residents provide valuable teaching contributions in the didactic, laboratory, seminar, and practice settings for the Doctor of Pharmacy programs. ${ }^{14}$ Data exist which suggest residents who acquire experience in a variety of teaching settings are more likely to choose a career in academia. ${ }^{18}$ Romanelli et al. describe a scholarship of teaching and learning certificate (STLC) program for pharmacy residents which provides them with formal training in becoming an educator. ${ }^{19}$ Components of the program include seminars on teaching methods, leadership of problem-based learning activities, preparation and delivery of didactic lectures, and the development of a teaching portfolio. A survey of Romanelli's program showed residents expressed a greater confidence in their teaching ability after completing the program compared to those residents who did not complete the program. ${ }^{20}$ McNatty et al suggest tailoring a STLC program to PGY1 and PGY2 residents so that residents have sufficient preparation for faculty and nonfaculty positions. $^{18}$

Another option for training residents and stimulating interest in teaching is to offer a residency rotation elective in teaching and learning. AACP collaborated with ASHP to develop goals and objectives for the PGY2 elective (adopted in 2008). ${ }^{21}$ AACP is also a partner in the Education Scholar faculty development resource. ${ }^{22}$ Several pertinent modules can be coupled for enrollment by residents or licensed to programs on behalf of their residents for use to satisfy the elective teaching and learning goals and objectives. Residency programs which have structured teaching rotations could share their objectives, outline of activities, and formal evaluation forms for others to adapt if interested. Considering the expansion of residency programs outside of academic medical centers, communitybased residencies with specific teaching programs would be of particular interest. Programs which already include and advertise a teaching certificate program as a required or optional component of their residency program include: University of Kentucky, Oregon Health and Science University, Medical University of South Carolina, Virginia Commonwealth University Health System, University of Florida, University of the Sciences in Philadelphia and multiple community-based sites (i.e. Meriter Health System, Monroe Clinic) in collaboration with the University of Wisconsin School of Pharmacy.

\section{Preparation for Practice Roles}

Partners, donors and participants. Based on the findings of the Pharmacy Manpower Project-sponsored conference on "Professionally Determined Need for Pharmacy Services in 2020," held in 2001, the need for pharmacists was projected to occur in the areas of order fulfillment, primary services, secondary and tertiary services, and indirect or other services. ${ }^{23}$ (See Table 1) A shortfall in available pharmacists as well as available residency-trained pharmacists by 2020 is expected. Traditionally, academia has partnered with academic medical centers and tertiary care healthcare systems to provide post-graduate pharmacy training; however, to meet the demand for residency-trained pharmacists in a variety of settings, partnerships need to be identified and developed in practice areas for which there is a predicted need for increased residency training. Partners can be identified in several areas: 1) practice settings in which training may occur, 2) educational settings from which education support may be garnered, and 3) funding entities or donors who enhance funding of post-graduate education. It is expected that some entities, such as academic healthcare centers, would fall into multiple categories.

Practice settings. Practice settings for the first postgraduate year (PGY1) should continue to expand outside of the traditional academic medical centers and healthcare systems. Although accredited residencies are available in the areas of community care (community pharmacy), managed care pharmacy practice, and managed care pharmacy systems, penetration into these areas may be limited. Aggressive pursuit of potential partners to expand the breadth of potential experiences (Table 1) should occur.

Educational partners. In addition to providing a practice setting with a patient population, partners are needed to assist in providing education in the areas of patient care, research, and teaching. Partners may be 


\section{American Journal of Pharmaceutical Education 2009; 73 (8) Article S4.}

Table 1. Pharmacy Practice Settings and Potential Partners ${ }^{\mathrm{a}}$

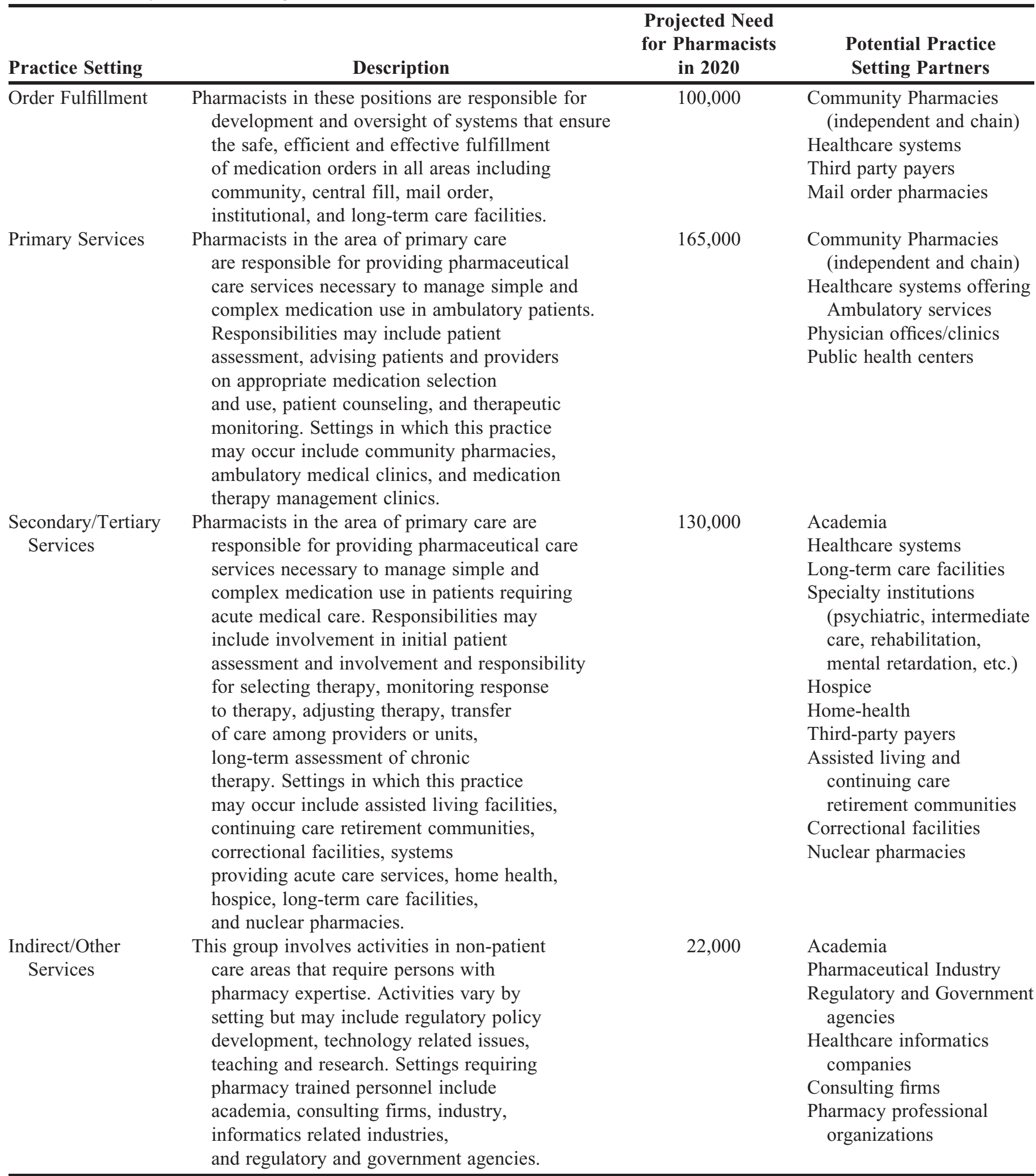

a Adapted from: Knapp DA. Professionally determined need for pharmacy services in 2020. Am J Pharm Educ. 2002;66:421-429.

needed to provide opportunities for interprofessional education. Although colleges/schools of pharmacy are the most likely partners in this area, partnering with other healthcare educators should be considered. These partners may include colleges of medicine, dentistry, and nursing and other allied health programs, and public 


\section{American Journal of Pharmaceutical Education 2009; 73 (8) Article S4.}

health degree programs. In particular, these programs can provide expertise enhancing resident education.

Funding entities and donors. Several mechanisms for funding residencies have been previously reviewed. ${ }^{2}$ Based on this review, potential funding partners have been identified and include the practice site, the educational partners and various outside agencies. Among these, the Centers for Medicare and Medicaid Services (CMS) Graduate Medical Education funds appears to be the most prominent; however, funding from this agency is available only for accredited PGY1 residencies and is available only to institutions providing acute care for institutions receiving reimbursement through Medicare Part A. This inhibits expansion into nontraditional settings. Other potential funding agencies include professional organizations, pharmaceutical industry, medication wholesalers, and third party payers. AACP and practice partner organizations continue to advocate for funding for PGY2 residencies.

Successful models of funding residency programs which involve innovative collaborations are worth sharing. Malecha et al. describe a unique joint venture between an industry setting and a university setting with each entity supporting half of the residency's expenses. ${ }^{24}$ Mallecha et al. describe this arrangement as mutually beneficial. Another example of collaboration between industry and a university setting is the Oncology Specialty Residency offered at the University of Kentucky, College of Pharmacy which is partially supported by Amgen Healthcare Institute.

\section{Tools and Enhancements to Support Participation}

One barrier to successful partnerships that could be addressed is that of the high "cost" of implementation and organization of the residency. Sites that are interested in developing a residency would benefit from the experience of predecessors. An AACP facilitated web-based database or "tool box" would be helpful in collecting, sharing, and extending successful practices. Several successful models of postgraduate pharmacy education have been previously identified, and examples of these models should be collected and provided for general use in the tool box. ${ }^{4,14}$ In addition, a mechanism should be available to collect and add additional models to the database as they are reported. The tool box could incorporate a centralized database of potential partners on a national, regional and local basis to facilitate matching willing partners. Examples of affiliation agreements, proposals, and materials outlining the expectations of the resident to each partner organization involved would be especially helpful to include in a tool box for others to reference.

Besides descriptions of successful partnership models, this tool box could contain readily searchable and downloadable examples of such items as evidence of how a college/school's educational mission was advanced by residency program participation/leadership, examples of affiliation agreements between participants with responsibilities of each partner delineated, successful accreditation documents, recruitment ideas or tools, forms used to manage the residency, and overviews of the specific interests of the possible participants and their motivation. The tool box could also be a repository for educational enhancements and curricular components such as the structured teaching programs for residents cited above. Residency programs could provide examples of their program organization, materials, feedback, and evaluation forms as part of the tool box.

\section{Raising Visibility of Academic Involvement}

The committee suggests several strategies for the Association to consider to encourage sharing of successful practices, to recognize and raise the visibility of our members' involvement in postgraduate professional education, and to assess the outcomes. Annual meeting programming, focused school poster, individual poster abstracts and special session presentations are means of communicating programmatic innovations, successful practices, program enhancements (e.g., teaching certificate element) etc. Furthermore, to encourage continued development and reporting of successful partnerships, AACP should continue the Call for Successful Practices strategy and consider creating a recognition program to identify and publicize successful partnerships in postgraduate pharmacy education.

If there is sufficient member interest, a Learning Community or Special Interest Group might be created for those members who are involved in residency program administration. The committee also suggests that AACP institutionalize data collection through the Institutional Research functions to capture structural/finance/human resources data to inform the extent to which the enterprise is involved and to inform structural models for academic participation. They suggest incorporating specific items in the graduating student survey to capture postgraduate training and further that the Association consider periodic outcomes studies on the faculty pipeline.

\section{CONCLUSION}

The committee recommends that the academy adopt a position supporting college/school contributions to quality and capacity in residency training. The committee also recognizes that residency training is an essential element in the preparation for practitioner-educator roles, but recommends that the academy take leadership for investigating the value proposition for residency training and return on investment to all stakeholders to make the case for external and internal support. 


\section{American Journal of Pharmaceutical Education 2009; 73 (8) Article S4.}

\section{RECOMMENDATIONS OF THE COMMITTEE}

\section{Policy Statement}

AACP supports activities by colleges and schools that enhance the quality and quantity of residency training programs in all pharmacy practice settings and recognizes that residency training is an essential element in the preparation for practitioner-educator faculty roles.

The committee carefully chose the wording of this policy statement which recognizes residency training as an essential element in the preparation path for practice faculty so that the policy is stated in parallel construction to an existing policy statement which recognizes residency training as an essential element in developing specialized practice roles (i.e., directed at practitioner development). The 1990 policy is stated previously in this report. Adoption of this policy statement by the House of Delegates provides the Association two companion policy statements supporting member college/school involvement in residency program quality and capacity with recognition of residency training as an essential element in preparation for 1) practice roles and 2) faculty roles. This outcome would be consistent with the intent of earlier recommendations cited previously.

Note: At the AACP House of Delegates meeting July 22,2009 , the policy statement was adopted with the following change in language:

AACP recognizes that residency training is an essential element in the preparation for practitioner-educator faculty roles and supports activities by colleges and schools that enhance the quality and quantity of residency training programs in all pharmacy practice settings.

Recommendation 1. Academic pharmacy needs to take leadership for articulating a pharmacy research agenda to demonstrate the value of postgraduate professional education.

Recommendation 2. AACP should collaborate with ASHP to track outcomes of residents.

Recommendation 3. AACP should encourage and support member colleges/schools to participate in residency training as a mechanism to increase capacity for experiential education and develop future preceptors for experiential education.

Recommendation 4. AACP should develop an electronic tool box that provides access to examples of successful partnership models as well as the tools (example contracts, responsibility delineations, core curricula, accreditation form examples, technology descriptions, etc.) that facilitate the development of new partnerships in postgraduate pharmacy education.

Recommendation 5. Exemplary academic-practice partnerships for residency training should be communi- cated, shared and recognized. AACP should create a forum for dialogue on successful practices of members in conducting residency programs.

Recommendation 6. AACP should systematically collect data through Institutional Research to increase visibility of the capacity and contributions of member institutions involvement in residency programs.

Recommendation 7. AACP encourages member institutions to develop combined residency/Masters degree programs to prepare workforce for leadership roles in practice, industry and academia.

Suggestion 1. Colleges and schools should be involved in providing systematic and ongoing access/interaction for PharmD students with residents - integrate residents into teaching, research and service responsibilities in the PharmD program.

Suggestion 2. Colleges and schools involved in conducting residencies with academic preparation component should track graduates and report outcomes.

\section{ACKNOWLEDGEMENT}

The committee wishes to acknowledge S. Whitney Zatzkin, MPA, MSR for research assistance in preparing this report.

\section{REFERENCES}

1. Reynolds JR, Briceland LL, Carter JT. Experiential education delivery - Ensuring success through support and development of the faculty and administrative team. Am J Pharm Educ. 2005;69:Article S9. 2. Nelson A, Godwin H, Gourley D, et al. Final report Deans Council Task Force on post graduate pharmacy (residency) education. Am J Pharm Educ. 2007;71:Article S06.

3. AACP Cumulative Policies 1980-2008. Policies on Postgraduate Education and Training. Governance, House of Delegates p.7. Available at: http://www.aacp.org/governance/HOD/Documents/Cumulative\% 2520Policies,\%25201980-2008.pdf. Accessed June 4, 2009.

4. Lee M, Bennett M, Chase P, et al. Final report and recommendations of the 2002 AACP Task Force on the roles of schools and colleges in residency training. Am J Pharm Ed. 2004;68:Article S2.

5. Commission to Implement Change Background Paper IV. Am J Pharm Educ 1993;57:386-399.

6. Accreditation Council for Pharmacy Education: Accreditation Standards and Guidelines for the Professional Program in Pharmacy Leading to the Doctor of Pharmacy Degree., July 1, 2007. Available at: www.acpe-accredit.org. Accessed June 4, 2009.

7. American Society of Health-System Pharmacists. ASHP longrange vision for the pharmacy workforce in hospitals and health systems: ensuring the best use of medicines in hospitals and health systems. Am J Health-Syst Pharm. 2007;64:1320-1330.

8. Murphy JE, Nappi JM, Bosso JA, et al. American College of Clinical Pharmacy's vision of the future: Postgraduate pharmacy residency training as a prerequisite for direct patient care practice. Pharmacotherapy. 2006;26:722-733.

9. ASHP 2008 Residency Match Information. Available at: http:// www.ashp.org/Import/ACCREDITATION/New.aspx. Accessed June 12, 2009. 


\section{American Journal of Pharmaceutical Education 2009; 73 (8) Article S4.}

10. Joint Commission of Pharmacy Practitioners (JCPP). Future Vision of Pharmacy Practice. November 10, 2004. Available at: http://www.aacp.org/resources/historicaldocuments/Documents/ JCPPFutureVisionofPharmacyPracticeFINAL.pdf. Accessed June 12, 2009.

11. Crossing the Quality Chasm: The IOM Health Care Quality Initiative. Available at: http://www.iom.edu/CMS/8089.aspx.

Accessed June 17, 2009.

12. Johnson TJ. Pharmacist work force in 2020: Implications of requiring residency training for practice. Am J Health-Syst Pharm. 2008;65:166-170.

13. Knapp KK, Cultice JM. New pharmacist supply projections: Lower separation rates and increased graduates boost supply estimates. J Am Pharm Assoc. 2007;47:463-470.

14. AACP 2008-09 Successful Practices in Pharmaceutical Education: College/School Involvement in Conducting Residency Programs. Available at: http://www.aacp.org/resources/education/ Pages/SuccessfulPracticesinPharmaceuticalEducation.aspx. Accessed June 3, 2009. Please see pp. 4-25; p.17; pp.26-32. 15. Anderson JC, James NA, Wouter van R. Customer value propositions in business markets. Harvard Bus Rev. 2006;84:90-99.

16. Capacity of hospitals to partner with academia to meet experiential education requirements for pharmacy students. Am J Pharm Educ. 2008;72:Article 117.

17. Doucette WR, Kreling DH, Schommer JC, Gaither CA, Mott DA, Pedersen CA. Evaluation of community pharmacy service mix:
Evidence from the 2004 national workforce study. J Am Pharm Assoc. 2006;46:348-355.

18.McNatty D, Cox CD, Seifert CF. Assessment of teaching experiences completed during accredited residency programs. Am J Pharm Educ. 2007;71:Article 88.

19. Romanelli F, Smith KM, Brandt BF. Certificate program in teaching for pharmacy residents. Am J Health-Syst Pharm. 2001;58:896-898.

20. Romanelli F, Smith KM, Brandt BF. Teaching residents how to teach: A scholarship of teaching and learning certificate program (STLC) for pharmacy residents. Am J Pharm Educ. 2005;69: Article 20.

21. ASHP Accreditation Standard for Postgraduate Year Two (PGY2) Pharmacy Residency Programs Goals and Objectives. http:// www.ashp.org/s_ashp/docs/files/RTP_PGY2AccredStandard.pdf. Accessed June 16, 2009.

22. American Association of Colleges of Pharmacy. Education Scholar-Teaching excellence and scholarship development resources for health professions educators. Available at: http://www.educationscholar.org. Accessed June 18, 2009.

23. Knapp DA. Professionally determined need for pharmacy services in 2020. Am J Pharm Ed. 2002;66:421-429.

24. Malecha SE, Cha AJ, Holt RJ. Establishing a combined drug information residency in industry and academia. Am J Pharm Educ. 2000;64:177-180. 